\title{
The Use ANd VAlue of Fiction IN \\ Greek and Roman History \\ Sobre uso y valor de la \\ ficción en la historia \\ griega y romana
}

Joaquín Muñiz Coello

Universidad de Huelva

coello@uhu.es - https://orcid.org/0000.0003-2984-6360

Fecha recepción 23.02.2018 / Fecha aceptación 26.11.2018

\section{Resumen}

Griegos y romanos conectaron con su pasado, en primer lugar, a través del poema épico. Éste, con los recursos que eran propios del género poético, caracterizó el modo de elaborar el relato historiográfico posterior. Así, ficción y realidad fueron los elementos que dieron forma a las historias que nos dejaron griegos y romanos. Intentamos aquí ofrecer las actitudes que los historiadores de Roma asumieron a la hora de compatibilizar la ficción con la evidencia, la fábula con la realidad, y su consecuencia en el relato historiográfico.

\section{Palabras clave}

fábula, historia, poesía, Livio, Dionisio de Halicarnaso.

\section{Abstract}

Ancient Greeks and Romans knew about their past primarily through the epic poem. With the poetic resources typical of this genre, it went on to typify the way in which the historical report was made. In other words, both truth and fiction became elements giving form to the histories of Greek and Roman authors. In this paper, we explore the Roman historians' attitudes in order to reconcile fiction with evidence, fable with fact and the consequences on the historical account.

\section{Keywords}

Fable, history, poetry, Livy, Dionysius of Halicarnassus. 



\section{Los griegos, entre la fábula y la historia}

Para los escritores romanos, el griego era un pueblo propenso al mito, a lo novedoso y admirable. Un pueblo que se complacía escuchando relatos sobre asuntos maravillosos, que le hacían trascender de su realidad cotidiana a espacios sólo accesibles desde la mente, donde los deseos podían verse realizados. Plutarco afirmaba que la Ciudad daba crédito a las cosas más absurdas, y en la misma línea Tácito explicaba que el rumor que en el año 32 se extendió por Acaya y Asia, de que había sido visto por allí Druso, el hijo de Germánico, que en realidad estaba en prisión en el Palatino desde dos años antes, era posible por la facilidad con que los griegos admitían como reales cualquier clase de rumores o hechos maravillosos, y se podrían sumar otros ejemplos que igualaban a griegos y romanos en credulidad.

La influencia que la fábula, entendida ésta como sinónimo de mito, fantasía, invención o mera patraña, mantuvo en la narrativa griega, se explicaba por el espíritu curioso e imaginativo de los griegos. Conocer el pasado estimulaba la atracción ante lo desconocido, para alguien siempre dispuesto a dejarse seducir por cualquier clase de habladurías y de cuentos, aun de los más ingenuos. Para Aristóteles, la prueba del irresistible atractivo de la fábula era que todos solían exagerar cuando daban cuenta de cosas sucedidas. Por nuestra parte, no creemos, como se ha llegado a suponer, que el estereotipo sobre la ingenuidad de los griegos y la relativa frialdad con que los romanos trataban a veces sus propios mitos, pudiera tener que ver con el hecho de que éstos últimos carecieran de una mitología tan coherente como la de los griegos, de que aquellos no dispusieran de un legado tal del que pudieran sentirse orgullosos como pueblo a la hora de evocarlo. Considerados globalmente, se piensa que los mitos griegos eran de ciudades y territorios, y estos entornos estaban conectados a su vez con una mitología panhelénica más amplia, mientras que los mitos romanos eran de lugar, y comprensibles en sí mismos sin sumisión a creencias superiores ${ }^{1}$.

1. El mito de Guillermo Tell es escandinavo, pero también suizo, P.G. Bietenholz, Historia and Fabula. Myths and Legends in historical Thought from Antiquity to the Modern Age, Leiden/New York/Köln 1994, 3; S. Price \& E. Kearns, eds., The Oxford Dictionary of Clasical Myths and Religion, Oxford 2003, p. xi-xii. Sobre la dificultad de definir la ficción, G. Currie, The Nature of Fiction, Cambridge 1990, 1-4. Sobre fábula y 
De todas formas, es un hecho que el legado mítico griego proporcionó a los romanos el argumento de muchos de los episodios que luego aparecieron insertos en las historias sobre los tiempos más antiguos de la Ciudad. Argumentos como el de Porsena, apoyando la causa de Tarquinio el Soberbio, el exilio de Colatino o el de Coriolano, fueron los paralelos de episodios griegos como la ayuda de Esparta al tirano Hipias, o los ostracismos de Hiparco y Temístocles, respectivamente, y los ejemplos se suceden. De esta manera, para un escritor romano era perfectamente compatible manifestar admiración y respeto por los poemas homéricos, y a continuación calificarlos sin más de fábulas, de relatos falsos, y hablar de Odiseo como el contador de mentiras que era, como las que contó a Alcinoo y los feacios².

Es sabido que los restos literarios griegos más antiguos se remontaban a Homero, y que fue igualmente poesía la actividad que dio continuidad al quehacer literario de al menos, los dos siglos siguientes, de los que nos han llegado numerosos fragmentos. Por su parte, la prosa no empezó a ser realidad hasta el siglo V, algunas décadas antes de Heródoto, a través de prosistas y logógrafos, de cuya existencia sólo sabemos lo que sobre ellos escribieron autores posteriores. En consecuencia, se piensa que el origen de la historia tuvo que ver con la poesía, entendida ésta como la expresión íntima de un autor, cuyo objetivo era conmover, deleitar y seducir al oyente con imágenes, símbolos, ficciones y relatos, tan irreales e increíbles como agradables de ser escuchados. La poesía, el poema épico en concreto, proporcionó el modelo de cuyos recursos los historiadores se aprovecharon para embellecer y hacer más atractivos sus relatos en prosa ${ }^{3}$.

Poesía e historia coincidían en tratar asuntos atractivos para el oyente o lector, que proporcionaban deleite para su espíritu. Los poetas también trataban los tiempos antiguos pero desde sus patrones estéticos, y con el paso del tiempo sus poemas se convertían en fábulas, que de esta forma se hacían más atractivos y agradables para quienes gustaban de esa clase de textos, en vez de enfrentarse a la exclusiva, fría y distante exposición de los sucesos. Así, el relato de la antigüedad dejaba de ser verosímil al presentarse mezclado con lo irreal, y la narración de los hechos probados y ciertos quedaba equiparada al relato fantástico, pareciendo que tal homologación de lo cierto con lo fantástico, fuera el coste necesario para preservar la memoria de lo realmente acaecido. Tucídides daba poco valor a la información sobre los tiempos anteriores a la Guerra del Peloponeso, que calificaba de míticos, aunque él mismo a veces echaba mano de ella. Para el historiador griego tras aquellas fábulas y leyendas, había

ficción sobre todo en la novela, L. Graverini, "Useful Truths, Enchanting FIctions: Historians and Novelists at Play", Classical Bulletin, 85.1, 2009, 11-26.

2. Plut. Numa, 15; Pol. IX.1-2, Tac. ann. VI [5.10]; Hor. ep. I.2.3-14; Plin. ep. VIII.24.3; Juv. XV.13-26; Arist. poet. 24. 1460a; 25. 1461b; P.G. Bietenholz, Historia and Fabula. op. cit. 3 y 49; R.M. Ogilvie, Commentary on Livy Books, 1-5, Oxford 1965, 46. T. P. Wiseman, "Lying Historians: seven Types of Mendacity", J. Marincola, ed., Oxford Readings in Classical Studies, Oxford 2011, 69.

3. Junto a Hecateo de Mileto, la lista de logógrafos incluye a Eugeón de Samos, Déyoco de Cícico, Bión de Proconeso, Eudemo de Paros, Democles de Figela, Acusilao de Argos, Carón de Lámpsaco y Ameleságoras de Calcedón, todos anteriores a Heródoto, y Ferécides de Atenas, Acusilao de Argos, Helánico de Lesbos, Damastes de Sigeo, Jenomedes de Ceos, Janto de Lidia y otros, coetáneos de Tucídides, todos igualmente del siglo V. La relación de historia y poesía, en B. L. Ullman, "History and Tragedy", TAPhA 73, 1942, 25-53. 
un fondo de realidad, aunque fuese difícil distinguir lo cierto de lo falso, o simplemente, que ante los impedimentos y el previsible precario resultado de su esfuerzo, el escritor no estuviese interesado en abordar esa tarea selectiva ${ }^{4}$.

Los filósofos griegos, incluyendo a Aristóteles, fueron indiferentes a la historia como disciplina. Para éste, poeta e historiador no diferían por el formato de sus escritos, verso o prosa, sino por la forma de contar las cosas, pues mientras el historiador las contaba tal como sucedieron, el poeta lo expresaba como creía que debían o debieran de haber sucedido. La historia recitaba acciones reales, igual que una forma de fábula como era la tragedia recitaba imitaciones de ellas. El poeta se refería a lo general y el historiador, a lo particular. En la historiografía posterior ambas visiones eran compatibles en un mismo relato. En su tratado de retórica, el estagirita afirmaba que los prodigios y fantasías servían para cautivar la atención de los oyentes del discurso, un fenómeno que no era exclusivo de los griegos, pues consta que este tipo de asuntos, como más arriba indicábamos, también fascinaba a la gente de los niveles sociales más bajos de la Roma de finales de la República. Gente que, a juicio de Cicerón, al carecer de esperanza de tener una carrera pública de honores, mostraba una gran afición por conocer la historia ${ }^{5}$.

\section{Fábula e historia}

Fabula o mito, términos aproximados pero no idénticos, según utilicemos terminología latina o griega, eran lucubraciones de la imaginación. Significaban tanto lo intrépido, lo excesivo y maravilloso, el prodigio, como la ficción melodramática, lo increíble, lo contrario a la certeza, a lo verosímil, a la verdad comprobada o corroborada, el reverso del objeto de la historia. El mito era un relato cantado o contado, con pretensiones de veracidad, que tenía un argumento tan fantasioso como emotivo, interpretado libremente por el autor, con detalles y evocaciones que podrían admitirse como verosímiles o incluidas de alguna forma en la esfera de la lógica y lo posible. El mito expresaba una realidad de orden distinto a la constatable, era

4. Embellecía un poeta como Homero, Cic. fin. V. 51-52; de orat. I.70; 154; 158; III.27; el mismo Tucídides, I.10; I. 21.2; 22.4, como Dionsio de Halicarnaso indicaba en su obra, DH Thuc. 51 ss.; Tac. Germ. II.3; Varrón, en apud Non. Marc. p. 77M= p. 107L; V. Max. II.1.9; Hor. Carm. IV.15.26/32; Plin. ep., II, 5, 5; Teofr. frag. 20 Schmidt; Quint. inst. X. 1. 27/28; P.A. Brunt, "Cicero and Historiography", (art. de 1988) J. Marincola, ed., Oxford Readings in Classical Studies, Oxford 2011, 210; A. Momigliano, Ensayos de historiografía antigua y moderna, México 1993, [Wesleyan University Press 1947], 168. Historia y poesía eran campos próximos, y en cierta manera la historia era un poema sin las formas vinculantes del verso, escrito para contar, ad narrandum, no para demostrar, non ad probandum, para la memoria de la posteridad y la fama del narrador con talento, Quint. inst. X.1.31, aunque ya lo advirtiera mucho antes Herodoto. Para responder a su fin, los relatos debían ser simples, breves, claros, plausibles, naturales y tener mucho equilibrio, Cic. orator, 124.

5. Arist. poet., III.7; 1.1447al7. 2; 1.1447bl6; 2.1448al; Rhet. 3.14.1415b2; Pol. IX.1-2; Cic. fin .V.51; Tac. ann. VI [5.10]; Hor. ep. I.2.3-14; Plin. ep. VIII.24.3; Juv. XV.13-26; M. I. Finley, "Myth, Memory, and History", HÆT 4.3, 1965, 281-302, 282; B.L. Ullman, "History and Tragedy", op.cit. 25-52, 29 y 33. 
una expresión con la que un individuo o un grupo social podían conformar su pasado cuando reflexionaban sobre sus raíces, una recreación imaginaria del modo en que una sociedad se vertebró desde el principio ${ }^{6}$.

Eran mitos o fábulas las comedias, las tragedias o las obras dramáticas, cuyo fin no era contar lo sucedido. Cuando en las representaciones escénicas se simulaban los problemas, afanes y zozobras cotidianas de la condición humana, estas obras literarias no pretendían ser testigos reales de los hechos. En el lado opuesto, el de los hechos probados, la historia constituía el logos, el relato racional y razonado en prosa, que describía los sucesos acaecidos desde la certeza de su veracidad. Ambas fórmulas de expresión coincidían en su intencionalidad, pues tanto el mito como la historia tenían pretensiones de autenticidad, cada una desde su esfera de conocimiento, y lo hacían desde el respaldo de una tradición, esto es, como continuadores de una forma de transmisión de episodios a través de generaciones ${ }^{7}$.

Fábula e historia diferían en que en la primera, nada era verificable, mientras que en la segunda todo debía serlo. Pero los historiadores tampoco podían obtener pruebas de la completa realidad de lo ocurrido, sino que igual que los pintores y fotógrafos, creaban una ilusión visible de los objetos tangibles, pues aquellos sólo podían transmitir una imagen más o menos real y cierta de lo acaecido. Una de las funciones del mito era hacer el pasado inteligible y pleno de significado, seleccionando de ese pasado unos pocos asuntos o temas, que a partir de ese momento adquirirían relevancia, permanencia y significado universal. Para los atenienses del siglo V eran más reales Agamenón, Edipo y Teseo que otros personajes posteriores, salvo Solón. Pese a que no se conservaba certeza de ninguno de aquellos, se pensaba que eran auténticos y podían estar conectados a hechos históricos documentados o lugares geográficos específicos ${ }^{8}$.

6. En las obras ficticias, debemos aceptar que el contexto histórico encaje dentro de lo posible, de modo que se nos presente como verosímil, porque ello refleja una forma de ver la vida, de entender los acontecimientos. La ficción en las novelas y romances de tiempos imperiales, G. Bowersock, Fiction as History. Nero to Julian, University of California Press, 1994, 51; M. Mazza, Il vero e l'immaginato. Profecía, narrativa e storiografia nel mondo romano, Roma, 1999.

7. Agust. CD VI.5.2; P.G. Bietenholz, Historia and Fabula. op.cit. 78. Pese a sus evidentes analogías, mito y fábula no eran conceptos completamente idénticos, pues mientras el mito se expresaba mediante un simbolismo complejo, la fábula ampliaba sus significados y en ocasiones contraponía personajes y animales en una alegoría mecánica, que proporciona una moral inmediata, M. Nojgaard, La Fable Antique. I. La fable Grecque avant Phedre, Kovenhavn 1964, 86; Plut. mor. 406E; Horacio afirmaba que las fábulas debían ser creíbles para resultar más atractivas al lector, Hor. ars poet. 338. P. Grimal, Diccionario de Mitología Griega y Romana, Barcelona 1965, xxv; P. Ovidio Nasón. Metamorfosis, trad. A. Ruiz de Elvira, Alma Mater, Barcelona 1964, p. x; C. Miralles, Introducción, Historia de la Literatura Griega, Madrid 1988, 13. Las mejores mitografías conservadas son la Biblioteca de Apolodoro de Atenas, autor del siglo II a.C., y las fabulae de Hygino, autor de tiempo de los Antoninos, A. Ruiz de Elvira, Mitología Clásica, Madrid 1975, 8 ss.

8. P.G. Bietenholz, Historia and Fabula, op.cit. 1 y 3; esto lleva a algunos hoy a calificar a la historia antigua, como obra escrita, de fábula convencional, W.S. Ferguson, "The Office of the Ancient Historian", CJ 5.6, 1910, 259-266, 261; vid. P. Munz, "History and Myth", Philosophical Quarterly, VI, 1956, 1-16; M. I. Finley, "Myth" op.cit. 281-302, 283-284. 
Fábulas por tanto, eran sucesos falsos, cosas que jamás habían sucedido, que habían sido inventadas. Hablaban de cosas que no habían pasado, pero usando personajes que el narrador podía caracterizar y revestir de los elementos reales, aquellos que definían la condición humana. De personajes y situaciones que con frecuencia combinaban lo verosímil con lo inverosímil. Así, usando de lances placenteros y agradables, se construía una ficción de episodios plausibles y probables con los que el oyente reavivaba su fantasía y obtenía un gozo estético. En la imaginación desplegada por el autor se hacía intervenir a seres naturales y sobrenaturales, con tramas que no perseguían la veracidad y exactitud de los hechos históricos, pero que tampoco se definían como contrarios a ellos. De hecho, tal combinación o convivencia de elementos antagónicos, lo irreal y lo real, lo cierto y lo fabuloso, podían conectarse y compartir el relato sin fusionarse, como dos formas distintas de representación de los sucesos. El analista romano Celio Antípatro, del tiempo de los Gracos, recogía en sus relatos muchos sueños que supuestamente luego se habían hecho realidad. Hacía suya la afirmación del historiador griego Sileno, cuando aseguraba que tras la toma de Sagunto, en un entorno de bestias salvajes, Júpiter se apareció a Anibal y le dio encargos de la asamblea de dioses. Para él, fábula y realidad podían ir perfectamente combinados en la narración, aquella como refuerzo de los contenidos de ésta, para azuzar el interés de los lectores. En las fábulas se contaban asuntos no acaecidos pero que podían suceder, y este era el fascinante atractivo que estimulaba la imaginación del público al que se dirigía. Así, fábula era el episodio de las mujeres de Lemnos que mataron a los varones de la isla, o la demanda del decenviro Apio Claudio sobre la joven Verginia. Pero también eran fabulae aunque de otro tipo, los chismes y rumores, las habladurías de la gente sobre los asuntos cotidianos que circulaban por la ciudad, y cualquier patraña o cuento que se refería como entretenimiento, con independencia de que estuviese basada o no en testimonios ciertos?.

Decía el arpinate que no se debía dar autoridad o crédito a cosas imaginarias, pues habían sido inventadas y propaladas a la ligera. La fábula trataba de asuntos no verosímiles ni reales, de afirmaciones que nadie había comprobado, se asociaba con una lectura agradable, y

9. Cic. div. I. 39; 49; 84; 123; II. 35; 101, 144; fam. VIII.8.1; Clu. 85; off. I. 114; el drama ceciliano, fabula caeciliana, Cic. Att. I. 16.15; eran fábulas la entrevista de Lucio y Publio Escipión con Antíoco, la naturaleza divina del segundo para los hispanos, el relato de Valerio Antias sobre los amores del cónsul L. Quinctio Flaminino y el joven Filipo el cartaginés, el discurso de Demetrio, hijo de Filipo V, a Perseo, la amenaza de guerra de los volscos durante la tramitación de la futura Ley Terentilia, y otras que el historiador reproducía advirtiendo que no era su intención ni confirmarlas ni rechazarlas. Livio, III.10.10; 44.9; V.21.9; X.9.13; XXVI.19.7;XXXIV. 2. 3; XXXVII.48.6; XXXIX.43.1; XL.12.9; 15.1; Rhet. Herenn. I. 13. Las fabulae en las comedias de Plauto y Terencio, la poesía y la tragedia, Isid. etym. I.40.3; Quint. Inst. II.4.2; Plaut. capt. 52; 54; 535; cas. 6; 8; 12; 17; men. 70; 724; 725; 1077; per. 788; poen. 718; las mentiras atribuidas a Clodio, fabula clodiana, Cic. Att. I.18.2; representar una farsa, vetus fabula, Cic. Att. IV.2.4. una obra de Livio Andrónico, Cic. Brut. 72; 73; una tragedia de Ennio, Cic. Brut. 79; las obras de teatro de Accio y Pacuvio, Brut. 129; fabula de Gyges, referida por Platón, Cic. off. III.38/39; Aristodemo, actor de fabulas, Gell. XI.9.2; Livio, VII.2-6-8, año 364 a.C.; Isid. etym. I.44.5; Festus, 268, 18; Gell. III.3.15; Phaedr. 1, prol. 2-3, M. von Albrecht, Historia de la Literatura Romana, [London, 1994] Barcelona 1997, vol. 1, 916. Rumores y habladurías eran las cosas de las que Tácito se quejaba de tener que tratar, en sus annales. 
se oponía a la historiografía. Pese a todo ciertos milagros que se contaban eran tenidos como auténtico en época de temor y miedo ${ }^{10}$.

\section{La poesía y el pasado}

Precisamente esta ausencia de líneas divisorias entre el quehacer de poetas y el de los prosistas, nos lleva a considerar que por algún tiempo la labor de ambos pudo estar solapada, mezclada, y que la poesía épica pudo ser asumida como argumento historiográfico, algo que los historiadores intentaron luego señalar y corregir. La presencia de una conciencia historiográfica supuso la voluntad de diferenciarse de la poesía. En el mundo helénico fue un hecho que durante mucho tiempo la épica sirvió como vehículo para conservar una versión del pasado, y las historias posteriores tenían que recurrir a ella para sus propias elaboraciones. En su introducción Tucídides subrayaba las diferencias entre su relato y las pomposas y encantadoras exageraciones de las obras de poetas o logógrafos como Hecateo, tan indemostrables, decía el ateniense, que con el tiempo, como supra dijimos, en su mayoría pasaban a los fabulosos dominios de la mitología ${ }^{11}$.

En los comienzos de la literatura romana, no hubo distinción entre quienes escribían en verso o en prosa, y los segundos eran globalmente considerados y nombrados como scribae. Sabemos que desde el 207, al final de la vida del poeta Livio Andrónico, «cuando la República alcanzó más prosperidad», se permitió a histriones y poetas que celebraran reuniones en el Templo de Minerva en el Aventino, construido hacia el 263, para que allí hicieran ofrendas en honor de aquel poeta tarentino, que escribía y representaba fábulas ${ }^{12}$.

10. Cic. fin. V.52; 64; div. I. 37. II.58; 113; inv. I.27.

11.Tuc. I.2-21; La opinión de Tucídides sobre logógrafos y poetas. A. Corcella, "The New Genre and its Boundaries: Poets and Logographers", Brill's Companion to Thucydides, eds. A. Rengakos and A. Tsakmakis, Leiden \& Boston, 2006, 33-56; T. Rood, "Objectivity and Authority: Thucydides' Historical Method", Brill's Companion to Thucydides, eds. A. Rengakos and A. Tsakmakis. Leiden \& Boston, 2005, 225-249; R. Nicolai, "The Place of History in the Ancient World", A Companion to Greek and Roman Historiography, ed. By J. Marincola, Oxford 2007, 14 y 15. Al no existir la novela, el romance invadió la oratoria y la historia, R.L. Roberts, "Tacitus' Conception of the Function of History", GઐR 16, 1936, 9-17. 9. La producción novelesca culmina con las aethiopicas de Heliodoro, a las que el autor dedica un apédice de su obra, G. Bowersock, Fiction as History. Nero to Julian, University of California Press, 1994, 51.

12. prosperius respublica populi Romani geri coepta est, Festus, p. 446-448L. En honor a Livio Andrónico, después del 207, año de la victoria en Metauro de Livio Salinator, hijo del poeta, los romanos fundaron un collegium poetarum, que acogía a scribae o autores de obras y actores, Festus, 492. Remains of Old Latin, II, E. H. Warmington, ed., Harvard University Press, 1967, xiii. Livio Andrónico murió hac. 204 a.C. Festus, 333L. En Plauto el término poeta designaba a alguien que hacía contratos, venía a ser una especie de artifex, architectus, Plaut. asin. 746 ss.; cas. 860; Pseud. 401, nosotros nos quedamos con el término escriba, en el más amplio sentido del término. E.G. Sihler, "The Collegium Poetarum at Rome", AJPh 26.1, 1905, 1-21. Con Augusto, el collegium poetarum, no pasaría de ser más que un club social, conservando quizás alguna de sus funciones primitivas, pero sin relación con la recitación de poesía o los asuntos literarios, y tendría 
Para Cicerón, fue precisamente éste el autor de la primera ficción poética, fábula en verso, presentada en público en el año 240, expresada en una serie de comedias, tragedias y una versión de la Odisea de Homero. Junto a él, se consagraron otros autores como Cneo Nevio, natural de Campania, que por los mismos años que Livio Andrónico dejó comedias y un relato en verso sobre la Primera Guerra Púnica - carmen belli punici -, en la que el propio autor habría participado. Al ser concebido como poema oral, el autor quedaba liberado de ser estricto con la realidad de los sucesos contados en el mismo. Esto mismo ocurría con la Farsalia, de Lucano, en tiempos de Nerón, poema épico pero no historia en verso. Junto a Nevio, aunque algo posterior - activo desde fines del siglo III y primer tercio del siglo II a.de C. - Quinto Ennio de Calabria, escribió dieciocho libros de annales sobre Roma, que iban desde la caída de Troya hasta su tiempo, igualmente concebidos como poema de la epopeya nacional. Partícipe como Nevio, de alguno de los episodios militares que narraba, Ennio ofrecía un argumento que combinaba con acierto la transmisión de sucesos antiguos con contemporáneos, usando las técnicas literarias del relato poético, para provocar deleite y agrado en los oyentes y lectores de sus escritos. Pero además Ennio nos dejó fragmentos de sus otras obras, veinte tragedias, dos comedias, cuatro libros de sátiras y varios poemas sueltos, que nos recuerda que los periodos iniciales, el relato del pasado seguía siendo una materia más de las abordadas por los escritores. Un sobrino de Ennio, Marco Pacuvio, dejó tragedias escritas en la primera mitad del siglo II, tiempo en el que florecieron otros autores de sátiras, como Cayo Lucilio, de Suessa Aurunca, en Lacio, y de comedias, tragedias y poemas sueltos, como el galo Cecilio Estacio y Lucio Accio de Pisauro. Este fue el ambiente literario donde surgió el interés por conocer el pasado de la Ciudad ${ }^{13}$.

El poema, en forma de comedia, tragedia, sátira, épica o poema suelto, fue por tanto claramente el formato de la más antigua expresión literaria romana. Sintetizadas como épica, tragedia y lírica, las tres podían compartir los mismos temas, que eran tratados desde enfoques distintos. La épica, que es la que aquí interesa, suponía una narración detallada y precisa, con minuciosas descripciones por ejemplo, de luchas, navegaciones, sacrificios, funerales y así, e incluía algún fragmento de verdad histórica, pero no un relato histórico propiamente dicho. Como el mito, la épica era eterna, atemporal, lo que ponía al escritor ante toda una gama de posibilidades y recursos literarios y artísticos, pues, como ya Suetonio escribía, cuando los primeros poetas escribieron sus obras, lo hicieron con un lenguaje

dos ordines, el de dos escribas y el de los poetas, Hor. sat. II.6.36-37, K. Quinn, “The poet and his audience in the Augustan Age", ANRW II.30.1, 1982, 75-180, 175.

13. Livio Andrónico, un griego de Tarento, 284/204 a.de C., Cic. tusc. I.3. Sabemos que el carmen belli punici de Nevio fue estructurado por C. Octavio Lampadio, autor del tiempo de los Gracos, en siete libros, según informa Suetonio. Suet. Gramm. 2.2. Se trataba de un poema que podría considerarse una primera historia de Roma apoyada en la certeza, T. P. Wiseman, "Lying Historians", op.cit. 74; H. Beck, "The Early Roman Tradition", A Companion to Greek and Roman Historiography, J. Marincola, ed., vol. I, Blackwell, Oxford 2007, 262; M. I. Finley, "Myth", op.cit. 281-302, 282 y 285; T.P. Wiseman, "The Prehistory of Roman Historiography", A Companion to Greek and Roman Historiography, ed. By J. Marincola, Oxford 2007, 74 y 75; A.W. Lintott, "Lucan and the History of the Civil War", CQ 21.2, 1971, 488-505, 488; Remains of Old Latin, E. H. Warmington, ed., Harvard University Press, 1967, t. I, 3-215; II, 45-156; III, 9-24. 
especial, solemne y brillante, y con ritmo más agradable, el mismo lenguaje que usaban para honrar a los dioses, aquellos a los que les dedicaban templos y grandes esculturas ${ }^{14}$,

\section{Historia y fábula}

La historia debía exponer lo ocurrido sin buscar otra cosa que el conocimiento del pasado. Para Polibio, la tragedia contaba cosas creíbles, pero no sucedidas, que apelaban al patetismo, y buscaba deleitar y conmover con detalles penosos, como hacía Filarco en su historia de Cleomenes; en definitiva pretendían ilusionar a los espectadores. Luciano de Samósata distinguía bien entre poesía e historia, que, decía, debían estar bien separadas, si bien la historia podía utilizar el relato grandilocuente y elevado si resultaba necesario para mejorar las descripciones, lo que identificaba al autor con la idea de una historia como discurso moldeado por la retórica. Poemas, comedias y tragedias contaban cosas que no necesariamente habían sucedido, pero que al hacerlo en el marco de la conducta humana, en un plano de actos y actitudes compatibles con la naturaleza, obtenían un cierto halo de proximidad, que el espectador asimilaba a la posibilidad y la certidumbre. Así, era fabula la historia de Pásifa y el toro, porque los amores de una mujer y un toro, y el resultado de esa una unión, un centauro, era contrario a la naturaleza; mientras que la leyenda de Fedra sería una ficción, pero no una fábula en el sentido que estamos viendo, porque los hechos que aquel argumento contaba, los amores de una suegra hacia su hijastro Hipólito y la muerte de ella, podían ser reales, darse en la sociedad humana, secundum naturam. Un narrador debía por tanto tener en cuenta los mitos, y permitir que realidad y ficción aparecieran combinados, sin que los historiadores lo cuestionaran ${ }^{15}$.

Al tratar los tiempos más antiguos de la Ciudad, la ausencia probable de fuentes de información más fiables llevó a los historiadores a incorporar el material disponible, que en su mayor parte estaba formado por fábulas y ficciones, un cúmulo de datos inventados, en tal grado que casi toda la tradición que nos ha llegado sobre los tiempos primitivos de Roma fue el resultado de sucesivas afluencias de fabulación. Desde Polibio a Estrabón, lo mítico era asociado a lo raro, lo extraño, excesivo, maravilloso o prodigioso, pero también a lo falso, melodramático, a la ficción, lo opuesto a lo histórico, a la verdad o análogo a la verdad, a lo creíble o probable ${ }^{16}$.

14. Suet. Poetas, proem.; A.W. Lintott, "Lucan", op,cit. 288.

15. Pol. II. 56. 6-12. ¿Por qué debo creer más a Heródoto que a Ennio?, se preguntaba Cicerón. Cic. div. II.116; Herodoto, un gran fabulador, para Gell. III.10.11; XVI.19.1; Lucian. Cómo se debe escribir historia, 8.20; 45.5-10; 9. 5-10.

16. T.P. Wiseman, Clio's Cosmetics. Three Studies in Graeco-roman Literature, Leicester and Totowa, 1979; A. J. Woodman, Rhetoric in Classical Historiography: four studies, London, Sydney and Portland, 1988, recogido en J.E. Lendon, "Historians without history: against Roman Historiography", The Cambridge Companion to the Roman Historians, 2009, 41-62, 41; S. Saï, "Myth and Historiography", A Companion to Greek and Roman Historiography, ed. By J. Marincola, Oxford 2007,78. 
Los analistas trabajaron sobre un material genuino de noticias, de extensión limitada, que, interpretado y ampliado, constituyó el grueso de la información elaborada en las historias de Livio y Dionisio de Halicarnaso. Estos explicaban el pasado desde el contexto de su presente, esto es, eran incapaces de imaginar un pasado cuyo escenario fuera distinto al que ellos mismos vivieron y conocieron. No sabían hablar de la Roma real o de la República Primitiva en términos diferentes a la Roma de su tiempo, algo que Tucídides, Polibio o Diodoro superaron, pues eran conscientes de que la historia significaba cambio y que los tiempos pasados no eran como los de su presente. Tampoco les interesó constatar la realidad o ficción de lo que narraban, limitándose a advertir de las versiones que discrepaban sin decantarse por una u otra. Para Livio, con relación a los hechos muy antiguos, era suficiente con que los datos fueran verosímiles, sin intentar asegurarlos o rechazarlo. Por ejemplo, como Dionisio desconfiaba de la veracidad del combate entre Horacios y Curiacios, lo contaba de la manera más verosímil, empleando recursos teatrales, y rechazaba directamente, por improbable, como típico material de mitos, el episodio de que sólo uno de los Fabios sobrevivió a Cremera ${ }^{17}$.

Al elegir como argumento de su obra la Roma primitiva, Dionisio de Halicarnaso aseguraba que iba a buscar la verdad para contarla. No se sentía constreñido por las fuentes documentales, como dijimos con Nevio, por lo que podía idealizar y embellecer el relato, y caracterizar el periodo tal como quisiera. En consecuencia, Dionisio dedicaba los primeros cuatro libros de los veinte del total de su obra a los mitos más antiguos. Igualmente Livio elaboraba el esquema de sus primeros libros sobre la base de mitos y fábulas. Diodoro de Sicilia dedicaba los seis primeros de su biblioteca a narrar los sucesos anteriores a la Guerra troyana, pura fábula, conectándolos sin tránsito con la historia posterior, como un continuum histórico. En realidad, todos los historiadores usaron las fábulas en mayor o menor medida, y no fueron coherentes al declararse cautelosos sobre las mismas y su utilización posterior, lo que nos indica la diferente concepción que los autores tenían sobre el método y los fines de la historia respecto de la que se tuvo en tiempos posteriores, y las necesarias cautelas a tomar a la hora de valorar aquellas historiografías ${ }^{18}$.

17. Livio, V.21.9; cf. praef. 6; para Livio los elementos irracionales enturbiaban la validez de los sucesos a los que acompañaban, según I. Kajanto, "God and Fate in Livy", Annales universitatis Turkuensis, series B, tom. 64, Turku, 1957, 52; J. Marincola, Historiography, a Companion to Ancient History, A. Erskine, ed., Oxford 2009, 13-22, 16; J. Marincola, "Ancient Audiences and expectations", The Cambridge Companion to the Roman Historians, 2009, 11-23, 19; J.E. Lendon, "Historians without history: against Roman Historiography", The Cambridge Companion to the Roman Historians, 2009, 41-62, 43; DH III.18.1, IX.22.3; es posible que al tratar de un pasado carente de veracidades, se sintiera justificado para idealizar, embellecer y caracterizar su relato, tal como quisiera, M. Fox, "History and Rhetoric in Dionysius of Halicarnassus", JRS 83, 1993, 31; J. Dillery, "Roman Historians and the Greeks: audiences and models", The Cambridge Companion to the Roman Historians, 2009, 77-107, 88.

18. "Los sucesos anteriores y los de mayor antigüedad, aún siendo imposible someterlos a una investigación seria, dada su lejanía, como testimonios fidedignos de una investigación retrotraída, pienso que no revistieron transcendencia ni en las guerras ni en lo demás", Tuc. I.1; II.15; 102; IV.24; VI.2; DH I. 6.5; 8.1. M. Fox, "History", op. cit. 31, DH I. 8.1, S. Saïd, "Myth", op.cit. 79 y 80. 
Para Livio, el límite entre fábula y realidad, entre poesía e historia, lo marcaba la intervención de los dioses en los asuntos humanos. El patavino admitía que el uso de fábulas podía, en alguna circunstancia, favorecer el análisis historiográfico. La retórica permitía hacer uso de fabulae poeticae, que embellecían el texto al sustituir el árido lenguaje con que solían transmitirse las noticias más antiguas. Con fábulas y mitos se colmaban las lagunas que originaban los parcos datos disponibles sobre los tiempos primitivos, superando así la eventualidad de una narración imperfecta. Si el autor carecía de noticias para cubrir un suceso, la fabula tapaba tal ausencia y aún realzaba el episodio, haciéndolo insignitius. Livio las incluyó con frecuencia, pero advirtiendo que ni las aceptaba ni las rechazaba expresamente, y que para él esta mezcla de lo cierto y lo increíble, de lo real y lo fantástico, era licencia que se permitía a quienes se ocupaban del pasado más remoto de la Ciudad. Además, no desdeñaba el hecho de que tal tipo de relatos, solían ser del agrado del oyente o lector y beneficiosos para la obra, ya que distendían la tensión impuesta por el tono narrativo, relajaban la agitación en el lector y podían recuperar la atención para el argumento principal. Las fábulas desempeñaban un papel retórico crucial, al servir de descanso o tregua en la monotonía de cualquier relato extenso, pues en estas pautas el narrador podía aprovechar para introducir digresiones sobre asuntos míticos, históricos o etiológicos, por ejemplo ${ }^{19}$.

La validez o no de la inserción de fábulas en los textos no se basaba en la realidad o ficción de los actos y actores que se describían, no era tanto un asunto de esencias como de las circunstancias que concurrieran en cada caso. Así, para Cicerón los oráculos recogidos desde Heródoto por el filósofo Crisipo, del siglo III a.C., no eran fidedignos ni tenían autoridad para ser creídos, mientras que el oráculo de Apolo en Delfos que respondió a una cuestión planteada por los atenienses, lacedemonios, tegeos, argivos y corintios, era cierto, porque si no, no habría sido tan concurrido ni famoso, ni el dios habría recibido tan grandes regalos si no se hubiese experimentado la veracidad del mismo. Lo mismo podemos observar en Varrón, que creía cierta la disputa entre Minerva y Neptuno sobre la ciudad de Atenas. En consecuencia, no había una pauta general absoluta para distinguir entre lo veraz y lo incierto, la verdad y la fábula, pues las circunstancias de un suceso podían ser decisivas para considerarlo real o ficticio ${ }^{20}$.

19. Livio, praef. 6-7; 13; fama rerum, VII.6.6; Diod. I.2.2; 69.7; Pol. XXXVIII.5.9; 6.1. Livio, por naturaleza el juez más imparcial de todos los grandes talentos, tributó a Cicerón un muy cumplido elogio, Sen. suas. VI.22. La parcialidad hacia unos u otros, la alta carga retórica de los discursos y narraciones de Livio, provoca grandes distorsiones en su obra,... las convenciones retóricas dominaban la historiografía romana, T.P. Wiseman, History, poetry and annals, D.S.D. Levene and D. Nelis, eds., Clio and the Poets: Augustan Poetry and the Traditions of the Ancient Historiography, Leiden and Boston 2002, 333; P. G. Walsh, "The Negligent Historian: 'Howlers' in Livy", Greece \& Rome, 5.1, 1958, 83; E. I. Johnston, "How the Greeks and Romans Regarded History", Greece \& Rome, 3.7, 1933, 38; D. A. Pauw, “The Dramatic Elements in Livy's History", AC 34, 1991, 33-49.

20. Cic. fin. V.52; 64; div. I. 37; II.58; 113; inv. I.27, A. J. Woodman, "Poetry and History, Cicero, de legibus 1. 1-5", From Poetry to History, Selected Papers, Oxford University Press, 2012, 7; era una historia non fabulosa sed historica ratio, August. CD XIII.9-10; 12; T.P. Wiseman, History, op.cit. 339. 
En suma, para Cicerón las fabulae en el relato histórico, del que se esperaba una certeza y veracidad comprobada, aportaban una información no desdeñable, sólo que de un nivel distinto al de las demás noticias en concreto. De esta manera, si la tradición transmitida en el siglo III por Teofrasto hablaba de Zaleuco, el legislador de los locrios occidentales, como un personaje real, que había existido y actuado en su tiempo - hacía el siglo VII a. de C. -, era indiferente que casi tres siglos después historiadores como Timeo negaran su existencia, pues lo relevante aquí era que los mismos locrios lo creyeran. Como en el caso del oráculo de Apolo, la confianza posterior en aquel suceso le proporcionó el grado de veracidad del que en principio carecía. Pero incluso aquellas fábulas que no proporcionaban deleite y que por sus contenidos resultaban excesivas, imposibles de creer, podían ser necesarias si servían para impresionar al pueblo ${ }^{21}$.

Ya supra dijimos que para ser admitida como alternativa de explicación de los hechos, una fábula debía contener elementos verosímiles y responder a lo que el hombre esperaba de la acción divina, en cualquier obra humana. La fábula por tanto, debía ser creíble. Cicerón admitía que los mejores hombres recibiesen, como premio por sus servicios a la comunidad, una naturaleza divina o semidivina. En consecuencia, aceptaba la tradición de que Rómulo fuera hijo de Marte, ya que en un determinado momento, al frente de un ejército, había sometido a la enemiga Alba Longa, matando al rey Amulio, lo que fue sumamente provechoso para la futura Roma, y de la misma forma la condición de héroe de Heracles era pago consecuente con los beneficios que derivaron de sus doce trabajos. Tampoco la Fortuna podía ser ajena a la trayectoria de triunfos y conquistas que avalaron la superioridad del estado romano durante el siglo II a.C., ni la intervención divina podía ser ajena a los preclaros orígenes de la Ciudad. Pero las demás tradiciones sobre Rómulo, su abandono en el río por orden del rey albano con su hermano Remo, atemorizado por la idea de que fueran ellos quienes le destronasen; el ser ambos amamantados por una bestia salvaje y que unos pastores les recogieran y educaran en los cultivos y labores del campo; su supuesta y excepcional fuerza física y la ferocidad de su carácter, que inspiraba en los demás obediencia y resignación, todo esto para el arpinate eran asuntos de utilidad nula, fabulae, cosas de la leyenda, en definitiva, sucesos que para el orador no estaba probado que hubieran ocurrido, y que debían ser considerados como inciertos. En consecuencia,

21. Se califica de poetas a Homero, a Aristófanes, de la vieja comedia, a Ennio, el más grande, y al parásito del IV acto de la comedia Los asnos, de Plauto, Plin.nat. XXI.29; Gell.V.1.6; Plaut.Asin.748; Cic. Balb.51. Gell. V.18.9; había tradiciones sobre la intervención de los dioses en sucesos humanos, que eran manifestación de su existencia, Cic. deor. I.30.83; II.2.6; 28.70; quod traditum est; de partitione oratoria, 11. 40; leg. II.6.15; fabula est, in qua nec verae nec veri similes res continentur, mientras que argumentum son cosas ficticios, imaginadas, pero que acaso pudieron ser reales, argumentum est ficta res, quaetamen fieri potuit, Cic. inv. I.19.27. Según T.P. Wiseman, "Roman Legend and Oral Tradition", JRS 79, 89, 130, a los mitos centrales que la tradición llevaba, se unían los mitos secundarios creados, no sin originalidad y destreza, por intelectuales que buscaban con ello dotar a sus trabajos de un cierto barniz de autenticidad y enjundia. Argumentum, materia poética de un drama, cuyo contenido no es lo que es, sino lo que pudo ser, M. von Albrecht, Historia de la Literatura Romana, [London, 1994] Barcelona 1997, vol. 1, 349. Vid. además, A. Szedegy-Maszak, "Legends of the Greek Lawgivers", GRBS 19, 1978, 199-209. 
Cicerón parecía supeditar la veracidad de algunos episodios, cuyo formato se adecuaba más al de la fábula que al histórico, a la utilidad práctica de sus contenidos, a si de ellos se podía obtener una enseñanza moral u ofrecer conductas ejemplarizantes ${ }^{22}$.

Para Diodoro era necesario tener en cuenta el mito o fábula si su inserción en las narraciones guiaba al hombre, por ejemplo, hacia la piedad o la justicia, y servían de ejemplo para que el lector llevara una vida más noble. De esta forma, las fábulas eran útiles si ayudaban a descubrir comportamientos edificantes. Plinio el Joven aseguraba que fábulas y mitos cautivaban a oyentes y curiosos, y cumplían con la función de atraer y mantener la atención de un auditorio, ya que el relato histórico continuado, monótono y sin brillo, al ser de audiencia o lectura poco placentera, por sí mismo solo unos poco lo apreciaban ${ }^{23}$.

La visión del geógrafo y etnógrafo Estrabón sobre la relación entre mito y realidad, entre fábula e historia, era ciertamente racional y coherente. Para él, mitógrafos y escritores de fábulas fueron preludio de los historiadores. Como ya escribiera Cicerón las fábulas eran otra manera distinta de abordar los sucesos, cuya virtud principal era que activaban la curiosidad humana, siempre atenta a absorber lo novedoso e insólito. Unos sucesos narrados por un buen poeta, con la habilidad necesaria para convertirlos en fascinantes y placenteros de escuchar, podían ser asumidos como modelos explicativos y como en el caso de Homero, concitar audiencias que llenaran teatros. Además, concluía el de Amasia, las fábulas mantenían el temor religioso en las mentes sencillas, lo que era extremadamente útil para el gobierno de las ciudades ${ }^{24}$.

22.Era más de admirar, que habiendo vivido Rómulo, según creía el arpinate, en tiempos de brillo intelectual, músicos y poetas, tiempos reacios a admitir la fabula, se admitiera sus conexiones con la divinidad, como justificación de su grandeza y talento, Cic. rep.II. 2.4; 10.18; 20; Serv. ad Aen. I.235; Quint. inst. II.4.2; Diod. I.2.7. Fortuna está presente a lo largo del relato histórico de Polibio; R.M. Ogilvie, “The sources for early Roman history", CAH VII.2, [1989], 2006, 23; vid. J. Martínez-Pinna, "La tradición literaria sobre los orígenes de Roma", Gerión 4, 1986, 329-340; D.B. Dietz, "Historia in the Commentary of Servius", TAPhA 125, 1995, 61/97. Plut. Rom. 12; 21; 28; Cam. 22; Numa, 4; Quint. Inst. II.4.2; Serv. ad Aen. I.235; Livio, I.11.8; 4.7; 34.8; V.22.6; XXIX.17.1-13; Gell. XVI.19.23; XX.7.1; Plaut. Amph. 15; 94; Herod. I. 31; Cic. tusc. I.92; div. I.43; II.98; deor. I.16.42; II.63; II.70/71; III.77; no se debe interrogar al poeta sobre la veracidad de los hechos que describe, Cic. de leg. I.1.4; rep.II.17; 20; Att. V. 12. 1-10, a Lucio Luceyo, pretor del 67, en el año 55; D. B. Dietz, Historia in the Commentary of Servius, TAPhA 125, 1995, 61-97, 66; el embellecimiento que proporciona la retórica al discurso histórico, el uso de un lenguaje florido y otros recursos suavizaba la monotonía narrativa y acercaba la historia a la poesía, Quintil. X.1.31; en el siglo III d.C. decía Herodiano que los historiadores en su mayoría buscaban la aceptación del público cuidando el vocabulario y el estilo, dejando a un lado la verdad de sus relatos, Herodian. historias, I.1. Agustín de Hipona recoge una lista de fabulae fictae, como las de Triptolemo y la serpiente, el minotauro, los centauros, las tres cabezas de Cerberus, la mirada de la Gorgona, Belerofonte, Pegaso, Anfión y su lira milagrosa, Dédalo e Icaro, Edipo y la Esfinge, Anteo, el hijo de la Tierra, y otras, Agust. CD XVIII. 12; fabulae fictae, 13; T.P. Wiseman, "History", op.cit. 335.

23. Diod. I. 2. 2-4; 3.1. Cic. leg. I.2.7; 3; 4; 5; 7; inv. I.25; 27; 39; Plin. ep. V.8.4.

24. Str. I.2.8. Fábulas eran los relatos de los marineros sobre monstruos marinos que supuestamente habitaban en el estrecho de Mesina; los cálculos que el astrólogo L. Tarucio de Firmo, matemático y filósofo de tiempos de Varrón, establecía para conocer el día y la hora exacta del nacimiento de Rómulo; lo que se 


\section{Conclusiones}

Los romanos se veían a sí mismos más comedidos que los griegos, a la hora de valorar las fábulas que acompañaban a cualquier relato poético o en prosa. Su parangón eran los griegos, que respondían al estereotipo de ser un pueblo propenso a creer cualquier cosa, estar abierto a la fábula y lo increíble. Esta innata curiosidad por lo desconocido, que vinculaban a lo oculto y misterioso, les animaba a intentar conocer su pasado y sus orígenes. Por su parte, los romanos se definían más fríos y distantes acerca de la fábula, pero la realidad es que tal posición no pasaba de ser una actitud que subrayaba el prejuicio con el que muchos valoraban lo helénico. La realidad es que la historiografía romana tomó y utilizó los modelos míticos griegos y sobre ellos además elaboraron los propios. No hubo por tanto tal diferencia, y en mayor o menor medida todos los autores echaron mano de aquellos episodios ficticios en sus relatos.

En Grecia, las primeras obras literarias fueron en realidad los poemas orales de Homero, adscritos a la segunda mitad del siglo VIII, y no hubo prosa al menos hasta el siglo V, unos decenios antes de la gran historiografía griega. La historia surgió conectada con aquella poesía, a través del poema épico, creado para transmitir el pasado, o mejor diríamos una visión del pasado, deleitando al oyente, a partir de un lenguaje que se construía accesible a la mayoría. Gracias a su formato fabuloso, el poema épico se convirtió en vehículo de transmisión de la memoria del pasado, un pasado ciertamente lírico y tal como el poeta lo sentía, pero que de otra manera su recuerdo se hubiera perdido. Así, el formato poético era el precio a pagar por la preservación del recuerdo de lo sucedido. La prosa despreció al mito, pero no prescindió de él, ni siquiera Tucídides. Para Aristóteles, la diferencia entre poeta e historiador no estaba en lo que contaban, sino en la forma de hacerlo.

contaba sobre el rey Numa y su relación con la ninfa Egeria, que la gente, embobada por su poder había llegado a tomar como ciertas; sucesos irreales, imposibles, como cierta clase de conexión entre hombres y dioses, como la fabula sobre Arión, el tañedor de liras de Ténaro, que circulaba entre corintios y lesbios, y se conservaban dos esculturas en bronce de un delfín y un hombre montado encima; el mito sobre el número de hijos de Níobe; las representaciones en las que intervenían dioses y hombres; el deseo expresado por Juno de querer ser llevada a Roma, cuando se trasladaban los despojos tomados a Veyes; la fabula del pastorcillo Endimión, en la que intervenían la luna y Zeus; la de Cleobis y Bitón, enseñada por los oradores en las escuelas; la multitud de dioses, revestidos con forma humana, con todos sus vicios y virtudes, que propiciaron las fábulas de los poetas. Tan ficticio e imaginario como caracterizar a los dioses con todos los vicios y defectos humanos,- odios, iras, matrimonios, genealogías, venganzas, aficiones -, algo despreciable y repudiado. Sucesos imaginados como los versos del poeta Butas sobre los fabulosos orígenes de las cosas romanas, donde hablaba de Amulio, Rómulo y Remo; la desaparición de Rómulo, lo que se contaba de Cleomedes de Astipalia, campeón olímpico y héroe de la ciudad, hacia el 492 a.C., isla del Egeo, y Aristeas de Proconeso, éste último poeta y viajero del siglo VII a. C., que estuvo por el sur de Italia, y del que se decía que podía salir de su cuerpo y volver a él a voluntad, invenciones a las que era muy aficionado Heráclides del Ponto, de la primera mitad del siglo IV. El episodio de Aca Larentia y los gemelos, el de de Espurio Tarpeyo, o la patraña del sueño de Eneas, citado por Pictor en sus anales griegos; la de la encina de Mario, la palmera que vio Ulises en Delos, el olivo de Atenas, la aparición de Rómulo al campesino Julio Próculo, el rapto de Orythias, hija del rey Erecteo, por Boreas, el dios del viento, cerca de Atenas o el águila que le colocó a Tarquinio el gorro de flámine, entre otros muchos. 
Los primeros escritores latinos, como Nevio o Ennio, fueron poetas, que cuando trataron del pasado, lo abordaban a través del poema épico. En Roma, el recuerdo de sus tiempos más antiguos se conservaba sólo en relatos fabulosos, y este fue el tipo de material que manejaron, primero los analistas de los dos últimos siglos de la República, y luego los historiadores de tiempos de Augusto. En las obras de éstos últimos, las fábulas estuvieron al servicio de la historia, siendo ésta una forma del discurso de la retórica. Fábula y realidad fueron compatibles en un mismo relato, pero aquella al servicio de ésta. La fábula construía episodios plausibles, revestidos con elementos fantásticos y ficticios, que lo hacían agradables e interesantes para el oyente. La fábula era útil, según las circunstancias del contexto. Podían ser tomadas como reales si mantenían la atención del lector, daba credibilidad a los sucesos, sustentaba el temor del ciudadano, o mostraba un bien general, un servicio a la comunidad o una situación aceptada por todos, alcanzando fines didácticos y sumando conductas edificantes. 